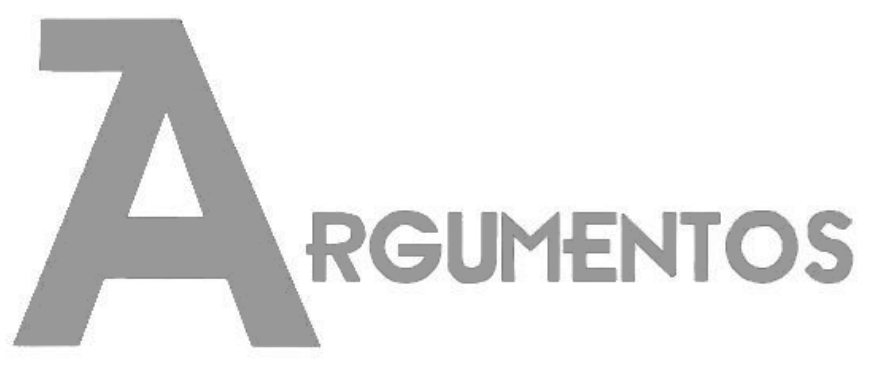

Vol. 18, n. 2, jul./dez. 2021 ISSN: 2527-2551 (online)

https://www.periodicos.unimontes.br/index.php/argumentos

\title{
O futebol como um instrumento de inserção étnica no Rio de Janeiro: 1888-1930
}

William E. Nunes Pereira ${ }^{1}$

Luiz Vinícius de Azevedo²

Recebido em: 03/03/2020

Aprovado em: 24/07/2020

Resumo: O presente estudo tem como foco a análise do processo de consolidação do futebol carioca ocorrido no período de transição entre os séculos XIX e XX, caracterizado pela apropriação e a reinvenção de um esporte de origem europeia pelo negro brasileiro, sendo fator importante para construção da identidade nacional, inserção social e do sentimento de representatividade étnica. Para realização da análise, fez-se uma revisão literária, relacionando as crônicas narradas por Mario Filho (2010), em que expressa a realidade do futebol no momento de consolidação no território brasileiro, com ênfase na cidade do Rio de Janeiro, à realidade social da comunidade negra. A partir do presente estudo foi possível evidenciar a estrutura segregacionista do esporte e como de maneira endógena a presença de jogadores negros nos gramados serviu para a criação de um gargalo de prestígio social para a comunidade negra, cujo passado escravocrata era extremamente recente e, portanto, suas consequências sociais se apresentavam de maneira mais clara e evidente.

Palavras-chave: Futebol; raça; hierarquia social; representatividade.

\section{El fútbol como instrumento de inserción étnica en Río de Janeiro: 1888-1930}

Resumen: El presente estudio se centra en el análisis del proceso de consolidación del fútbol en Río de Janeiro durante el período de transición entre los siglos XIX y XX, caracterizado por la apropiación y reinvención de un deporte de origen europeo por parte de brasileños negros, siendo un factor importante para la construcción de la identidad. nivel nacional, inserción social

\footnotetext{
${ }^{1}$ Bacharel em Direito e Economia. Especialista em Administração (Gestão dos Recursos Humanos). Mestre em Economia. Doutor em Ciências Sociais. Professor Associado do Departamento e do Programa de PósGraduação em Ciências Econômicas. E-mail: wenpereira2014@gmail.com.ORCID: https://orcid.org/00000002-2870-4742.

2 Bacharel em Ciências Econômicas pela Universidade Federal Fluminense - PUCG e mestrando pelo Programa de Pós-Graduação em Economia da Universidade Federal do Rio Grande do Norte, Brasil. Email: azevedolvinicius@hotmail.com. ORCID: https://orcid.org/0000-0003-1179-4785.
} 
y sentimiento de representatividad étnica. Para realizar el análisis se realizó una revisión literaria, relacionando las crónicas narradas por Mario Filho (2010), que expresaba la realidad del fútbol en el momento de consolidación en el territorio brasileño, con énfasis en la ciudad de Río de Janeiro, a la realidad social de la comunidad negra. A partir del presente estudio se pudo evidenciar la estructura segregacionista del deporte y cómo de manera endógena la presencia de jugadores negros en los campos sirvió para crear un cuello de botella de prestigio social para la comunidad negra, cuyo pasado esclavista era sumamente reciente $y$, por tanto, sus consecuencias sociales fueron más claras y evidentes.

Palabras clave: Fútbol; raza; jerarquía social; representatividad.

\section{Soccer as an instrument of ethnic insertion in Rio de Janeiro: 1888-1930}

Abstract: The present study focuses on the analysis of the consolidation process of football in Rio de Janeiro during the transition period between the 19th and 20th centuries, characterized by the appropriation and reinvention of a sport of European origin, by the Brazilian black, being an important factor for the construction of national identity and the feeling of ethnic representativeness. In order to carry out the analysis, a review of Mario Filho's work "O Negro no Futebol Brasileiro" was made, in which the author breaks down the reality of the sport at the time when football is implanted in Brazilian territory, with emphasis on the city of Rio de Janeiro, and the whole movement of social transformations caused by the professionalization process. From the present study it was possible to highlight the segregationist structure of sport and how endogenously the presence of black players served to break segregationism, generating social prestige for black players, whose slave past was extremely recent and, therefore, its social consequences were presented more clearly and clearly.

Keywords: Soccer; ethnicity; social insertion; representativeness.

\section{Introdução}

A sociedade brasileira do fim do século XIX era um reflexo do eurocentrismo que moldou a geopolítica ocidental e por consequência refletiam as ideias raciais europeias (STEPAN, 2004) ${ }^{3}$. O futebol, hoje uma das instituições de identidade nacional, não se desvencilha de tal herança histórica e surge, no Brasil, como um esporte recreativo que reproduzia todos os efeitos de dominações sociais históricas em que sobrepunha a imagem do homem branco cis como a representação de "normalidade" social. A influência europeia se fazia muito presente na composição do esporte, assim como na sociedade carioca, onde imigrantes e filhos dos mesmos foram atraídos para o território brasileiro, incentivados pela parceria comercial existente entre Brasil e Inglaterra, produção cafeeira intensa e pela indústria nascente no período. Os ingleses, por exemplo, começaram a chegar muito cedo aos países da América Latina, ainda na época

\footnotetext{
3 "Como nação culturalmente dependente, o Brasil era fortemente influenciado pelas ideias raciais da Europa, da França em especial. Wilson Martins $(1978,5: 6)$ observa que os brasileiros tendiam a 'viver vicariamente sua própria existência, como se fossem uma imagem refletida no espelho'”. (STEPAN, 2004).
} 
Artigo | O futebol como um instrumento de inserção étnica no Rio de Janeiro: 1888-1930 (PEREIRA, William E. Nunes; AZEVEDO, Luiz Vinícius de)

das grandes navegações e alcançaram uma larga influência no Brasil, que foi muito acentuada entre os anos de 1835 e 1912 (CARVALHO, 1982).

Buscando expor a hierarquização social promovida não só a partir das relações sociais, mas também por meios institucionais, o estudo se propõe a evidenciar como endogenamente o talento de jogadores negros quebrou barreiras sociais e, com o avanço das relações econômicas no futebol, criou um gargalo para inserção étnica, se configurando como um importante instrumento, também, para a valorização do sentimento de autoestima e representatividade de uma comunidade preta historicamente tratada como inferior. Marco importante no desenvolvimento da sociedade carioca, onde o eurocentrismo se via presente como expressão da naturalização da superioridade racial, já defendida no meio acadêmico (GONÇALVES, 2015).

Dessa forma, o estudo está divido em quatro partes, além da introdução e considerações finais. Inicialmente, busca-se, sustentado nas discussões de Florestan Fernandes (2008), Marco Aurélio Santos (2015); Nancy Leys Stepan (2004), Paulo Cesar Gonçalves (2014) e Petrônio José Domingues (2001), contextualizar as principais dificuldades que se apresentavam para a comunidade negra no Brasil pós-abolição da escravidão, visto que, apesar de ter perdido o principal razão econômica para existir, o racismo ainda era - e continua sendo - praticado por todas as esferas sociais, políticas e institucionais.

Na segunda seção, sustentado em Antônio Jorge Soares (1999), Carlos Molinari (2018), João Manuel Malaia Santos (2010), Leonardo Pereira (1998) e Mario Filho (2010), busca-se evidenciar a estrutura hierárquica presente na sociedade brasileira, inspirada em um eurocentrismo, refletida em uma de suas extensões: o futebol. Tratando a realidade do esporte antes de ser tratado como profissão, mas já consolidado como um esporte presente na cultura do Rio de Janeiro, e apesar da existência de alguns clubes que internalizavam a pluralidade social nas peladas entre os trabalhadores das fábricas (como o Bangu A.C.), tinham como praticantes majoritários no estado, clubes elitistas e segregacionistas.

A terceira seção, como extensão da discussão tratada na seção anterior, trata as transformações sociais que a popularização do futebol desencadeou na sociedade carioca, onde o talento do jogador de futebol negro, como figura central, abriu um caminho de oportunidades para a inserção social de toda uma comunidade de homens 
Artigo | O futebol como um instrumento de inserção étnica no Rio de Janeiro: 1888-1930 (PEREIRA, William E. Nunes; AZEVEDO, Luiz Vinícius de)

negros historicamente excluídos. Por último, apoiada em Judith Butler (2000), Silvio Almeida (2019) e Ricardo Gonçalves (2015), separou-se uma seção para discutir o papel da representatividade na vida social, o conceito de raça e os impactos e consequências sociais da estrutura que define os padrões de "normalidade" e "anormalidade". Além de provar o impacto do futebol para a desconstrução, ainda incipiente, de tal padronização como meio de dominação social ainda presente nos dias atuais, porém mais evidente no início do século XX.

\section{O contexto social para a população negra no Brasil}

A vida, a paisagem e a cultura dominante no Brasil historicamente foram influenciadas pelos europeus, sobretudo a influência inglesa, portuguesa e francesa. Portanto, é natural que a sociedade brasileira do fim do século XIX tenha carregado consigo alguns estigmas e heranças culturais europeias. O foco desta seção, entretanto, se limita à discussão da principal herança para a comunidade negra brasileira: o racismo.

A abolição da escravidão, em 13 de maio de 1888, apesar de sua homologação ter objetivos político-econômicos envolvidos, se apresenta como fruto de conflitos sociais e políticos cuja pressão de movimentos da sociedade civil, da luta abolicionistas, das fugas em massa das fazendas, e até da oposição dos militares provocaram crises políticas no governo imperial (SANTOS, 2015), materializando o anseio por liberdade de uma comunidade que há séculos vinha sendo expropriada, explorada e desumanizada 4 . Entretanto, tal homologação não a livrou das condições e estruturas sociais que mantinham a imagem inferiorizada do negro e, mais que isso, o Estado brasileiro não se preocupou nem com o suporte necessário para a nova classe de trabalhadores assalariados, que foi impedida não só de acumular bens materiais, mas de possuir terras, construir redes de relacionamentos, e de repente se via em uma estrutura socioeconômica competitiva sem o básico para atuação e com uma estrutura social e política que a invisibilizava.

Pelo contrário, nos anos anteriores à homologação da Lei Áurea "os problemas políticos que absorviam diziam respeito a indenizações e aos auxílios para amparar a

\footnotetext{
${ }^{4} 700$ mil escravos haviam sido emancipados (STEPAN, 2004).
} 
Artigo | O futebol como um instrumento de inserção étnica no Rio de Janeiro: 1888-1930 (PEREIRA, William E. Nunes; AZEVEDO, Luiz Vinícius de)

'crise da lavoura'” (FERNANDES, 2008, p. 04), onde, no imaginário dos proprietários de terra e cafeicultores, haveria necessidade de troca da mão de obra empregada nas lavouras, dado o novo arranjo do mercado de trabalho. A resposta estatal aos interesses dos cafeicultores, ou até mesmo para implementação de um projeto eugênico no país (STEPAN, 2004), veio a ser a imigração europeia, criando-se uma propaganda para atrair mão de obra europeia visando preencher as vagas de trabalho, agora assalariado, na lavoura, sobretudo na cultura cafeeira do Estado de São Paulo. Para isso, financiou-se transporte, colônias e subsídios aos produtores de café, como evidencia Paulo Cesar Gonçalves (2014):

O Estado foi chamado a promover, endereçar e organizar a imigração transoceânica, tornando-se fiador, em relação aos proprietários de terras, do abastecimento constante de braços para a plantação. É a partir desse momento que a política imigratória paulista sofreu, na prática, mudança de rumo, passando a financiar a obtenção de braços para a lavoura. Tarefa de grande vulto - como mostram as entradas anuais de imigrantes a partir de 1887 - que só o Estado teria condições de desenvolver, como instrumento de ação dos fazendeiros. (GONÇALVES, 2014, p. 07).

Dessa forma, no pós-abolição, os recém-libertos se viam em uma dicotomia entre se inserir novamente no sistema produtivo, com condições análogas às anteriores, ou incorporar-se à massa de desocupados ou semi-ocupados da economia de subsistência. Florestan Fernandes (2008) expõe que mesmo nas regiões mais prósperas do país, vide São Paulo e Rio de Janeiro, onde se tinham condições de um "autêntico mercado de trabalho", a comunidade negra deveria concorrer com um exército de reserva de "trabalhadores nacionais", além da mão de obra europeia, tida como mais acostumada ao trabalho assalariado e afeita às implicações econômicas e sociais do mesmo, fazendo com que vagas fora da lavoura para ex-escravos fossem mínimas. Ou seja, embora tenha sido marco histórico para os direitos humanos no Brasil, a abolição escravocrata não trouxe o sentimento de humanização e liberdade que a comunidade negra desejava, ela na verdade reforçou e remodelou as opressões e dominações sociais sobre os negros, se utilizando do aparelho estatal para manutenção dessa realidade, em que os excluía da vida econômica ativa e, portanto, da vida social que o capitalismo poderia oferecer. 
Artigo | O futebol como um instrumento de inserção étnica no Rio de Janeiro: 1888-1930 (PEREIRA, William E. Nunes; AZEVEDO, Luiz Vinícius de)

Com a conhecida Lei das Terras, posterior à interrupção do tráfico negreiro em 1850, a dominação social além de tirar todos os direitos de concorrência capitalista, tirou o direito dos negros às terras no país, onde se determinara que a terra deixasse de sem um bem social para tornar-se um bem privado, em que o negro por motivos óbvios se encontrava à margem desse mercado. O Estado além de promover a imigração europeia que, independentemente do objetivo de "clareamento" da população, aumentou a concorrência pelas vagas de emprego, foi indiferente frente a realidade avassaladora de insegurança social da população negra, se alinhando ao interesse dos proprietários de terra e fazendeiros, camada socioeconômica dominante no país, em que se representava sobretudo uma elite branca europeizada.

Florestan Fernandes (2008), em uma visão generalizadora, aponta que o impedimento do contato com relações econômicas e sociais que o capitalismo pressupõe fez com que os negros tivessem anseios pré-capitalistas. A massa de trabalhadores libertos, segundo ele, não apreciava "trabalhos degradantes", que imigrantes não se importavam em ocupar, como engraxar sapatos, vender peixes e jornais. São Paulo, mesmo como incipiente capitalista no Brasil, onde ideais de trabalho livre e iniciativa individual eram predominantes, com a visão de que a liberdade econômica seria o motor que superaria o atraso da economia brasileira, não era vista como um lugar de novas oportunidades de vida para a comunidade negra. Fernandes (2008) alude para o fato de que até os negros que se inseriam no mercado de trabalho (seja como autônomo ou como assalariado) tendiam a não prosperar pela falta de visões empreendedoras que movimentavam as relações comerciais ou pelos anseios "précapitalistas". Isto é, os anos de opressão e injúria podem ter abalado a relação psicossocial entre um setor da comunidade negra e o trabalho na sociedade brasileira do fim do século XIX, fazendo com que se levantassem barreiras sociais referentes ao trabalho negro principalmente na sociedade, mas também internas a eles, reproduzindo alguns laços de dominação e dependência, fazendo com que as "condições psicossociais e econômicas que cercam a emergência e a consolidação da ordem social competitiva na cidade de São Paulo tornavam-na [tornassem-na] imprópria e até perigosa para as massas de libertos que nela se concentravam." (FERNANDES, 2008, p. 34-35).

Essa consequência social dos anos de exploração, no pós-abolição, acabava por reforçar o imaginário racista de inferiorização da comunidade preta, uma vez que 
Artigo | O futebol como um instrumento de inserção étnica no Rio de Janeiro: 1888-1930 (PEREIRA, William E. Nunes; AZEVEDO, Luiz Vinícius de)

anseios pré-capitalistas em uma sociedade capitalista competitiva são tratados como fracasso, mas também ajudou a criar o imaginário de democracia racial, em que brancos assumiam uma postura paternalista de tutela do negro. Domingues (2001) expõe que instituições políticas, como o fim da escravidão e a proclamação da república, e sociais acabaram por criar e consolidar o mito da democracia racial, entre elas destacam-se literaturas estrangeiras, como a do francês Louis Couty, em que descrevia o Brasil como um país de igualdade racial, tanto nas relações como nas oportunidades, o movimento abolicionista, representado por Joaquim Nabuco, em que exaltava o clima harmônico entre as diferentes etnias no Brasil, o que poderia explicar aspectos que reforçavam a ideia da democracia racial: relações de dependência e paternidade de antigos senhores ou imigrantes e um setor da comunidade negra, que devido à proximidade que alguns negros tinham com as famílias de comerciantes, proprietários de terras e imigrantes, buscavam ajuda para suas realizações econômicas, ajuda essa que comumente excluía a necessidade de movimentos negros com a justificativa de que "todos somos iguais", o que acabou por evitar a construção de consciência racial, a criação de movimentos e revoltas da comunidade negra, consolidando a ideia de democracia racial ao mesmo tempo em que a comunidade negra era excluída socialmente ${ }^{5}$.

Os trinta anos posteriores à abolição escravocrata é justamente o período de intensificação da urbanização e início do processo de industrialização das cidades brasileiras e, com isso, evidenciaram-se problemas sociais urbanos - a miséria e falta de saúde da população trabalhadora, em sua maioria negra -, para além do campo e da lavoura. "Muitos juntaram-se à corrente migratória dos pobres sem profissão que fugiam para as cidades, onde competiam em condições desfavoráveis por empregos com mais de um milhão e meio de imigrantes brancos que entraram no país entre 1890 e 1920." (STEPAN, 2004, p. 336).

A própria condição precária em que a população negra foi deixada, corroborou para o círculo vicioso de preconceito na sociedade brasileira, sendo este um dos motivos para o surgimento de movimentos eugênicos no Brasil. A autora Nancy Leys Stepan, ao analisar a insurgência da eugenia no Brasil, associa a fundação da primeira sociedade

\footnotetext{
${ }^{5}$ Desdobramentos contemporâneos acabam por esclarecer atuação do racismo como estrutural, presente nas raízes sociais, assim como todas as suas instituições, uma vez que se consolidou por um processo histórico, político e ideológico, o que ajuda a compreensão das relações sociais atuais e mais ainda dos séculos XIX e XX. Ver a obra "Racismo Estrutural” de Silvio Luiz de Almeida (2019).
} 
Artigo | O futebol como um instrumento de inserção étnica no Rio de Janeiro: 1888-1930 (PEREIRA, William E. Nunes; AZEVEDO, Luiz Vinícius de)

eugênica no Brasil, em 1918, a quatro fatores principais: (i) Primeira Guerra Mundial, se relacionando com o sentimento de patriotismo e reinvindicação de maior protagonismo brasileiro no cenário internacional; (ii) Problemas sociais - a pobreza, a migração, a imigração e o desemprego - abriram caminho para um período de radicalização, onde a elite se associou uma agenda política de bem-estar social como forma de "aprimorar o povo brasileiro"6; (iii) O estágio de desenvolvimento da ciência brasileira, associado ao entusiasmo generalizado pela ciência como 'sinal' de modernidade cultural, principalmente a "ciência sanitária"; e (iv) A hibridez racial do país, associado ao tratamento de inferiorização com que o país sofria no exterior, sobretudo na Europa, “o Brasil era tido como exemplo ideal da 'degeneração' que ocorria em nações tropicais racialmente híbridas." (STEPAN, 2004, p. 338).

O futebol quando surgido como momento recreativo, nesta perspectiva, não fazia parte das ocupações da comunidade negra, pelo contrário, era um esporte europeu, praticado em sua maioria por europeus e exclusivamente branco. Mas no decorrer do seu desenvolvimento, com a competitividade e o surgimento de relações econômicas a estrutura do esporte se modificou, não apenas atraindo a comunidade negra para a prática e observação, como criando um gargalo para o sentimento de autoconfiança, autoestima, representatividade e, sobretudo, de ascensão e prestígio social negro, a partir da ocupação enquanto jogador de futebol, como exposto no decorrer do trabalho.

\section{O futebol enquanto instrumento de hierarquia social no Rio de Janeiro}

Nesta seção, busca-se evidenciar a estrutura hierárquica presente na sociedade carioca, inspirada em um eurocentrismo, refletida em uma de suas extensões: o futebol. E, mais que isso, expor a realidade do esporte antes de ser tratado como profissão, como momento de lazer e descontração que, apesar do possível pioneirismo de Thomas

\footnotetext{
6 "Tradicionalmente, as elites educadas receavam a violência e o perigo que representavam os negros e mulatos, retratados como preguiçosos, doentes, bêbados e em permanente estado de vagabundagem". (STEPAN, 2004, p. 337).
} 
Artigo | O futebol como um instrumento de inserção étnica no Rio de Janeiro: 1888-1930 (PEREIRA, William E. Nunes; AZEVEDO, Luiz Vinícius de)

Donohoe $^{7}$ em Bangu, marcada pela pluralidade social nas peladas entre os trabalhadores das fábricas, tinham como praticantes majoritários no estado, clubes elitistas ${ }^{8}$.

No contexto da cidade do Rio de Janeiro, a obra "O Negro no Futebol Brasileiro", do cronista Mario Filho (2010), apesar de possuir uma postura mais memorialista, lúdica e nacionalista do período - por tratar o futebol como um instrumento de conciliação racial, influenciado pela ideia de democracia racial -, evidencia as relações hierárquicas da sociedade refletida na composição de alguns clubes de futebol cariocas. As questões étnicas e socioeconômicas, dependendo da forma em que assumia em cada clube, foram balanceadoras para a formação social dos clubes e isto acabava por se tornar uma via de expressão da hierarquização da sociedade carioca. O autor analisa, por exemplo, a composição do Rio Cricket e do Paissandu, onde apenas europeus poderiam se associar e jogar futebol por tais clubes, com uma exceção na Grande Guerra, cuja convocação para o exército, de ingleses e alemães por seus países, facilitaram a entrada de um brasileiro na equipe de futebol do Paissandu.

No Brasil, em geral, os esportes foram introduzidos como uma característica de desenvolvimento social, ligados ao mundo civilizado e, portanto, seus praticantes deveriam ser os membros das elites sociais (SANTOS, 2010). A prática regular de esportes, com a formação de clubes nas principais cidades do país, ocorre no fim do século XIX, e serviu para distinguir os detentores do "status" de civilizado e moderno do restante da população, isto é, surge enquanto uma instituição voltada para "reforma do corpo e das mentes" (SEVCENKO, 1998, p. 571), mas, concomitantemente, reproduzia o racismo e elitismo presentes na estrutura social, onde aqueles detentores de conhecimento e capital para formação dos clubes marcavam as distancias entre os associados e a população. Sendo assim, quando o futebol assume posição central nesses clubes esportivos, inclusive com a formação de "Football Clubs", sua prática ainda não

\footnotetext{
${ }^{7}$ Como relata Carlos Molinari (2004), há indícios de que Thomas Donohoe, um escocês, técnico em maquinaria têxtil, contratado pela Companhia Progresso Industrial do Brasil, tenha introduzido a prática do futebol em 1894 no subúrbio do Rio de Janeiro.

${ }^{8}$ É importante ressaltar, entretanto, a existência, já na primeira década do século $X X$, de clubes do subúrbio e, portanto, com menos rigidez social em sua composição, como Bangu A.C., Esperança F.C., Brasil A.C. e Cascadura F.C., Club Atlético do Méier, São Cristóvão F.C., Pedregulhense F.C., entre outros.
} 
Artigo | O futebol como um instrumento de inserção étnica no Rio de Janeiro: 1888-1930 (PEREIRA, William E. Nunes; AZEVEDO, Luiz Vinícius de)

estava associada à lógica econômica e comercial, mas sim à lógica de simbolismo social do "status", da modernidade e da superioridade.

Deve-se se destacar o papel integrativo de alguns clubes de futebol, como, por exemplo, o Bangu A.C., por ter uma colônia inglesa menor, próxima a Companhia Progresso Industrial e se localizar mais perifericamente na cidade do Rio de Janeiro, não possuía tamanha rigidez no tecido social de sua composição. Inicialmente, o clube tinha como finalidade a diversão dos empregados britânicos da Companhia, mas conforme os esportes, sobretudo o futebol, recebiam apoio da fábrica, logo o clube expandiu sua adesão de sócios, absorvendo trabalhadores das demais origens e etnias (PEREIRA, 1998). Mesmo que em sua partida oficial de estreia, em 1904, seu time inicial possuísse apenas dois brasileiros, o clube é marcadamente conhecido pela acessibilidade dada aos negros e trabalhadores de sua fábrica de classes sociais menos privilegiadas, sendo um dos primeiros clubes a ser campeão com jogadores negros na equipe, conquistando a segunda divisão do campeonato carioca de 1911 e o do primeiro clube do Rio de Janeiro a escalar um jogador negro, Francisco Carregal, em 1905, mesmo sendo o único brasileiro e negro, no meio de cinco ingleses, três italianos e dois portugueses (FILHO, 2010).

É importante salientar ainda que, embora alguns clubes tenham aceitado incorporar sócios e jogadores negros, ainda assim, por vezes, a postura racista se mantinha. Antônio Jorge Soares (1999), ao realizar sua crítica às histórias que constituíram as tradições, inclusive à obra de Mario Filho, e serviram de base aos "novos narradores" (novos estudiosos) do futebol levanta uma implicação de Joel Rufino dos Santos (1982) sobre a postura dos clubes que absorviam os jogadores negros, onde se tinha preferência aos negros de pele clara9

O cuidado que os primeiros clubes tiveram ao recrutar estes elementos tapaburacos é curioso: não podia ser preto, naturalmente; nem procurado pela polícia. Mulatos serviam desde que fossem excepcionais com a bola no pé (e, como o célebre Carlos Albeno, pudessem embranquecer com pó de arroz). Ah! Uma coisa importante: tinham que jogar à europeia, repetindo os

\footnotetext{
${ }^{9} \mathrm{O}$ estudo usa o pressuposto de que negros são todos aqueles que possuem ascendência africana, desde que a assim se identifiquem e, por isso, pardos, se identificados enquanto afrodescendentes, são negros de pele clara. A distinção de tonalidades de peles negras também se faz pertinente devido ao tratamento diferenciado- exposto na citação - aos negros retintos.
} 
Artigo | O futebol como um instrumento de inserção étnica no Rio de Janeiro: 1888-1930 (PEREIRA, William E. Nunes; AZEVEDO, Luiz Vinícius de)

movimentos e jogadas ensinadas pelos folhetos ingleses que se vendiam junto com o material de jogo. (SANTOS apud SOARES, 1999, p. 133).

Mario Filho (2010) faz uma análise da foto desse time, evidenciando que os europeus pareciam despreocupados com suas aparências, "talvez por orgulho de raça superior", enquanto Francisco parecia se preocupar bastante, tido como o mais bem vestido dos jogadores. Um tecelão, cargo de baixo potencial financeiro, aparece de chuteiras novas (na época, botas), meias de lã e calções novos. Essa preocupação estética, para melhor inserção social, era frequente, sobretudo entre os negros - de qualquer tonalidade de pele -, buscavam se apresentar de maneira "mais arrumada", para serem reconhecidos como naturais, ou ao menos aceitos, ao meio em que conviviam. Arthur Friedenreich, por exemplo, considerado o primeiro ídolo da seleção brasileira, também tinha hábitos estéticos, cuja finalidade seria o "disfarce da negritude". (FILHO, 2010. p.58).

Como diversão, o futebol tinha custos, variantes de acordo com o local em que se praticava, e essa discriminação de preços entre os clubes explicava a composição social dos mesmos. A discriminação se manifestava claramente, também, através das preferências dos associados, cada jogador procurava clubes em que se sentiam representados entre si e nos casos em que não se encontrava representatividade nos clubes, se fundava um. Mario Filho expõe sua condescendência com algumas atitudes que critica ao trata essas preferências, às vezes, com naturalidade, citando o Fluminense como um "clube de homens feitos. De responsabilidade." (FILHO. 2010. p. 37). De qualquer forma, se torna evidente a reprodução da hierarquização social, étnica e econômica, visto que os jogadores ao procurarem seus iguais e excluir os diferentes, se utilizavam do dinheiro para manutenção dessa organização.

Deslocando a análise sobre os torcedores, quando o esporte passou a ser visto com bons olhos pela sociedade brasileira não havia essa separação na escolha dos clubes que torceria. Podia se torcer para qualquer time, pobre poderia torcer para o Fluminense, por exemplo, as restrições que existiam era sobre jogar, reservado para classes sociais mais privilegiadas, e nestes tipos de clubes, para brancos. A diferenciação social entre torcedores aparecia nos estádios. Mario Filho (2010) aponta, sem evidenciar exatamente o período referenciado, uma diferenciação entre geral e arquibancada, 
Artigo | O futebol como um instrumento de inserção étnica no Rio de Janeiro: 1888-1930 (PEREIRA, William E. Nunes; AZEVEDO, Luiz Vinícius de)

entre pobres e ricos, respectivamente, nos estádios, João Manuel Malaia Santos (2010) ainda inclui o surgimento de arquibancadas exclusivas para sócios, onde os clubes de elite tinham o intuito de se opor à democratização do futebol, prezando a exclusividade da prática do esporte, o que posteriormente culminará num conflito político entre profissionalismo e amadorismo do futebol. Apesar de qualquer um poder assistir os jogos, se via uma presença maior de torcedores na arquibancada, "A geral quase vazia, um torcedor aqui, outro ali, unidos pela distância que os separava da arquibancada, toda florida." (FILHO. 2010. p.44). Além disso, a propaganda dos jogos normalmente era voltada para atração do público rico, onde se via nos registros sociais "o nosso grand monde estava presente" ${ }^{10}$, exaltando a presença das altas classes sociais no estádio.

O Bangu A.C. parecia apresentar uma postura diferente entre os torcedores, em seu estádio geral e arquibancada se misturavam, até porque eram assentos de madeira, em torno do campo da Rua Ferrer. Porém, o comportamento de sua torcida, segundo Mario Filho, era peculiar, gerando a fama do "ganha, mas não leva", embora haja uma discussão sobre isso ter sido uma hipérbole do cronista ${ }^{11}$. Segundo ele, teria se tornado comum a invasão de campo e da estação de trem, pelos torcedores ameaçadores quando derrotados pelos clubes da cidade. Nesses casos jogadores não queriam sair dos barracões (vestiários da época) sem a companhia da polícia, pedras eram arremessadas nos trens, e nessa confusão o time vencedor não se preocupava em pegar o troféu que a partida oferecia, originando a expressão "ganha, mas não leva". O ato foi visto como espécie de luta de classe inconsciente pelo autor, onde a rivalidade se expressava entre clube do subúrbio e clube da cidade, porém, como relata, só era alimentada do lado do subúrbio, o que culminou em um distanciamento dos mesmos, já que os jogadores do Bangu não se viam em situações iguais, não se sentia do mesmo grupo social, "se viam diferentes como pessoa" (FILHO, 2010. p.44).

Tal diferenciação social é tratada pelo autor, como estopim para o surgimento do troféu João Ferrer para disputa somente de clubes pequenos, de trabalhadores, porém, a

\footnotetext{
10 "Também a propaganda que se fazia era para a arquibancada. Nas folhas, com o seu registro social, 'o nosso grand monde estava presente', e lá vinham nomes de senhoritas de os ornamentos da sociedade. (...) Era essa gente que o Fluminense e o Botafogo queriam." (FILHO, 2010. p.44).

${ }^{11}$ Carlos Molinari, em uma live para o canal "Castores da Guilherme", separa um comentário sobre os atos de vandalismo do Bangu nas estações de trem, onde argumenta que teria acontecido apenas uma vez, mas marcado o clube. Disponível em https://www.youtube.com/watch?v=cv458iQ3z1o\&t=1s acessado em 14 de agosto de 2020.
} 
Artigo | O futebol como um instrumento de inserção étnica no Rio de Janeiro: 1888-1930 (PEREIRA, William E. Nunes; AZEVEDO, Luiz Vinícius de)

primeira edição da taça João Ferrer é datada em 1907, ano de proibição da inscrição de "pessoas de cor" no campeonato carioca, como exposto na nota emitida pela Liga Metropolitana e publicada na Gazeta de Notícias do dia 18 de maio de 1907. Então, a criação da taça João Ferrer não foi apenas uma decisão baseada numa falta de identificação social, numa diferença entre time grande e pequeno, foi uma resposta à decisão da liga, oferecendo uma alternativa de campeonato em que negros pudessem ser inscritos. Molinari (2004) expõe a nota discriminatória:

Comunico-vos que a diretoria da Liga, em sessão de hoje, resolveu por unanimidade de votos que não serão registrados como amadores nesta Liga as pessoas de cor. Para os fins convenientes ficou deliberado que a todos os clubes filiados se oficiasse nesse sentido a fim de que cientes dessa resolução de acordo com ela possam proceder. (MOLINARI, 2004, cap. 1907)

O racismo se expressou de diversas maneiras em sua época amadora, além do respaldo jurídico que as liga cariocas ofereceram para tal. Um dos relatos no livro de Mario Filho (2010) é o do jogador Manteiga, negro, marinheiro que tinha boa técnica, ganhando o apelido de "Manteiga" devido ao seu passe refinado. Sua presença no time principal do América no ano de 1921 foi motivo de lutas e cisões internas ao clube, jogadores se recusaram a jogar ao seu lado, torcedores se recusaram a torcer pelo clube, havendo uma migração de jogadores para o Fluminense, berço da elite carioca.

Outro relato do livro foi um caso envolvendo o jogador Isabelino Gradín, figura que aparecerá como destaque de representatividade mais a frente, negro de "uma equipe uruguaia" ${ }^{12}$, que veio ao Rio de Janeiro jogar uma partida contra o Fluminense. Embora Mario Filho não tenha se preocupado em dar detalhes sobre a partida, o autor relata que em uma dividida pela bola, Gradín acaba dando uma cotovelada em Rivadária Corrêa, cuja maneira de revidar foi chamá-lo de "negro fedorento". O cronista relata que nada fez Gradín, assim como qualquer outro negro que jogava futebol, pois "negro não podia se ofender, brigar em campo. Senão apanhava, saltava gente da geral, da arquibancada, de bengala levantada para dar nele". (FILHO. 2010. p.109).

\footnotetext{
12 Muito provavelmente o Peñarol, visto que Gradín foi campeão uruguaio pelo clube em 1918 e 1921.
} 
Artigo | O futebol como um instrumento de inserção étnica no Rio de Janeiro: 1888-1930 (PEREIRA, William E. Nunes; AZEVEDO, Luiz Vinícius de)

\section{A popularização do futebol carioca e a oportunidade criada por jogadores negros}

A popularização do futebol foi um caminho natural, e que inicialmente não ameaçou a soberania elitista na composição dos chamados grandes clubes, pelo contrário, acentuava ainda mais as diferenças entre as instituições grandes e pequenas. As partidas de futebol ganhando cada vez mais importância no meio social, geraram "brincadeiras" ${ }^{13}$, que vezes se travestiam de humilhações aos derrotados, após as partidas, o que influenciava o comportamento já citado de alguns jogadores que se sentiam "menos brancos" nos times, buscando, além de naturalização no ambiente, fugir de situações em que se sentiriam desconfortáveis. Isso aumentou também a competitividade das partidas. Todos buscavam fugir das humilhações, e a vitória em campo era a melhor forma de espantá-las. Aparecendo, também, a partir daí algumas apropriações brasileiras do esporte, uma vez que o meio social passava a se envolver com o esporte. Nesse ponto, então, o esporte, em sua organização e na cultura de maior parte dos jogadores, se apresentava como um reflexo da sociedade em que estava inserida, reproduzindo seus conceitos pré-definidos de forma segregativa. A competitividade que o futebol estava adquirindo, apesar de contribuir para uma seriedade da recreação, acabou por expor as diferenças entreos grupos sociais, o que acabava por reforçar o discurso hierárquico-social, uma vez que clubes de composição social privilegiada sobressaiam-se aos pequenos clubes $^{14}$.

Conforme o futebol adentra na estrutura social como um esporte central na vida carioca, os jogos passaram a arrecadar um volume considerável de renda, a ponto de despesas de outros esportes do clube ficarem dependentes das bilheterias dos jogos de futebol. João Manuel Malaia Santos (2010) mostra relatórios do Fluminense F.C. onde, em 1913 , conseguiu arrecadar $36: 320 \$ 000$ com bilheterias e mais $4: 895 \$ 100$ com o aluguel do campo, o que comparado com montantes arrecadados nas décadas posteriores seria um baixo nível de arrecadação, entretanto, só era possível atingir tal nível de arrecadação a partir do futebol, e maximizado pela vitória e com títulos. Ou

\footnotetext{
${ }^{13}$ Datadas por volta de 1917, segundo Mario Filho (2010).

${ }^{14}$ (...) O futebol não mudava a ordem das coisas, pelo contrário. Onde se via melhor demonstração de que tudo era como deveria ser? (...) A superioridade de raça, da raça branca sobre a raça preta, a superioridade de classe, da classe alta sobre a classe média, da classe média sobre a classe baixa. A baixa lá em baixo, a alta lá em cima, vencendo, tirando campeonatos. (FILHO. 2010. p.68)
} 
Artigo | O futebol como um instrumento de inserção étnica no Rio de Janeiro: 1888-1930 (PEREIRA, William E. Nunes; AZEVEDO, Luiz Vinícius de)

seja, possuir bons jogadores, boas instalações, bons materiais de treinamento, técnicos e departamento especializados eram vantagens que poderiam fazer o clube arrecadar ainda mais, aumentando, portanto, a competitividade das partidas. Para ter uma equipe competitiva, então, barreiras étnico-sociais teriam de ser derrubadas, ou flexibilizadas, abrindo espaço para negros e pobres praticarem cada vez mais o futebol, uma vez que "A sobrevivência dos clubes, seu crescimento e sua afirmação dependiam das rendas produzidas pelas partidas de futebol". (SANTOS, 2010. p.54).

Além da esfera econômica, o gol do título de Arthur Friedenreich, contra o Uruguai do Sul-Americano de 1919, foi um instrumento importantíssimo para a abertura do caminho para uma naturalização da inserção do negro no futebol brasileiro, assim como para a popularização do esporte no país. Mario Filho (2010), de forma lúdica, aponta como o caminho de uma democratização racial no esporte que, segundo ele, ocorreria de forma lenta e gradativa, em oposição às pretensões dos grandes clubes ${ }^{15}$. Porém, é importante salientar novamente que a democracia racial no Brasil era um ideal presente no início do século XX, devido à abolição escravocrata e à proclamação da República, que em tese revogava o principal instrumento de opressão racial e universalizava o direito à cidadania, mas, na pratica, se caracterizava como um mito com raízes, principalmente, na passagem de viajantes que passeavam pelo país e produziam suas literaturas, reforçado pela elite intelectual e política brasileira, pelo movimento abolicionista institucionalizado e pelo processo de mestiçagem, uma vez que a realidade da comunidade negra pós tais marcos históricos era de marginalização, opressão e desigualdade.

Apesar da importância dessa representatividade de Friedenreich, outros episódios podem ser citados antes mesmo de 1919, que aos poucos abarcava jogadores negros no contexto do futebol carioca. O Campos Atlético Associação, de Campos dos Goytacazes, com menos visibilidade que Friedenreich, cujas cores roxa, preta e branca, simbolizavam a união das etnias, com o roxo representando o pardo, veio a ser campeão do Campeonato Campista de 1918, com todos os jogadores negros, e ainda compondo cargos diretivos, inclusive com mulheres (MACHADO, 1981). Mario Filho destaca que foi

\footnotetext{
${ }^{15}$ A popularização de Friedenreich demonstrou ao brasileiro que "o futebol devia ser de todas as cores, futebol sem classes, tudo misturado, bem brasileiro." (FILHO. 2010. p.69). Tal popularidade, segundo o autor, se deu mais pelo fato de ser um jogador pardo jogando futebol do mais alto nível pela seleção brasileira, do que pelo próprio gol sobre o Uruguai.
} 
Artigo | O futebol como um instrumento de inserção étnica no Rio de Janeiro: 1888-1930 (PEREIRA, William E. Nunes; AZEVEDO, Luiz Vinícius de)

a Seleção Brasileira o primeiro time a ser campeão com jogadores negros no elenco, porém, o Campos A.A. um ano antes já havia conquistado um título e não só com um jogador, mascom a maioria da equipe formada por negros. Mais que isso, foi o primeiro clube a ter negros compondo cargos na diretoria do clube e mulheres em sua fundação ${ }^{16}$. Outro clube marcado na história como campeão com jogadores negros é o já citado Bangu A.C., conquistando a taça João Ferrer, em 1907, e a série B do campeonato carioca em 1911.

Como o futebol passou a ser competitivo pela popularidade, a partir da segunda metade da década de 1910, a rotina de um jogador passou a ser cansativa para manutenção da conciliação de uma vida trabalhista e de atleta, forçando muito jogador a trabalhar menos, abandonar o trabalho ou abandonar o futebol. Um processo de desenvolvimento do esporte que favoreceu aqueles que eram estudantes, de família rica, com tempo e de pouco desgaste físico diário para continuarem a jogar futebol. 0 perfil estudante do jogador de futebol se tornou maioria no esporte sobre jogadores que trabalhavam e era o perfil no qual as instituições do futebol da época buscavam, tal supremacia de jogadores estudantes estava explícita no time do Botafogo que ganhou o campeonato carioca de 1910, onde apenas três jogadores trabalhavam.

Possuir jogadores estudantes passou a ser uma vantagem competitiva dos clubes, visto que estes tinham disponibilidade para treino mais frequente e intensa. A Escola de Direito, inclusive, tinha horários flexíveis. "Parecia que o horário da Escola de Direito tinha sido feito para jogadores de futebol. Somente duas cadeiras por dia. Uma de duas às três, outra de três às quatro. Às vezes, só de duas às três." (FILHO. 2010. p.83). O que fez com que outros grandes clubes assumissem a postura de compor times de maioria estudante, para competir em maior nível. E se via razão, dava para se entender o culto ao estudante, o Flamengo foi bicampeão, nos anos de 1914 e 1915, com um time majoritariamente de estudantes de medicina. Mas, essa vantagem de ser estudante não era propriamente derivada do estudo ou somente do tempo de treino, era consequência, também, porque tinham uma vida de conforto, devido à condição familiar que os jogadores dos clubes considerados grandes tinham. A partir de então

16 Clubes pioneiros na inserção do jogador negro no futebol brasileiro. Disponível em: http://www.observatorioracialfutebol.com.br/historias/clubes-pioneiros-na-insercao-do-jogadornegro- no-futebol-brasileiro/ Acesso em 18 nov. 2018. 
Artigo | O futebol como um instrumento de inserção étnica no Rio de Janeiro: 1888-1930 (PEREIRA, William E. Nunes; AZEVEDO, Luiz Vinícius de)

passaram a adotar medidas para a admissão dos jogadores, analisava-se o desempenho técnico, tempo disponível para treino e comportamento pessoal, características técnicas, de viabilidade e social, respectivamente, onde, pelo o que vimos, o caráter social de tal contratação tinha características segregacionistas. Os jogadores dos clubes considerados menores, principalmente os clubes de fábrica, como o Bangu, Andaraí e o Carioca, pela necessidade de se trabalhar, não tinham a possibilidade de treino todos os dias, como os grandes, mas as fábricas passaram a facilitar a rotina de seus atletas, através de dispensa nos horários de treino, sem que percam a hora de trabalho, e delegando funções menos cansativas no processo produtivo. (REIS et al, 2013).

Entretanto, os cargos mais leves das fábricas não eram destinados para todos os jogadores, a "sala do pano" era para seletos jogadores, na maioria dos jogadores ficavam responsáveis pelos teares, até que os treinos começassem. As notícias sobre a valorização do trabalhador/jogador proliferaram rapidamente, contribuindo para uma popularização crescente do futebol, não apenas como diversão, mas também enquanto possibilidade de se conseguir um emprego na fábrica. "Os garotos que jogavam no largo da igreja sabiam que, quando crescessem, se fossem bons jogadores de futebol, teriam lugares garantidos na fábrica." (FILHO, 2010. p.85).

Na década de 1920, se tornou normal a "contratação" de jogadores, ainda em um período em que o futebol não era profissional, os jogadores passaram a receber ofertas financeiras, fosse por meio do "bicho" (recompensas financeiras oferecidas posteriormente às vitórias), prática existente até hoje, porém muito ligada à conquista de títulos, ou pelo emprego nas casas comerciais dos sócios, em bancos, usinas, no comércio em geral, como forma de gratificação salarial. Esses atletas recebiam regalias, como a dispensa de horários rígidos, para que pudessem se empenhar nos treinamentos diários.

Buscando impor os aspectos de "normalidade" no futebol, a Liga Metropolitana criou medidas para dificultar a participação de quem não fosse estudante nas competições oficiais. Normas foram criadas, desde 1907 e mais intensamente nas décadas de 1910 e 1920, visando excluir jogadores pobres, negros e/ou analfabetos. Um dos critérios estipulados para tal seletividade foi a assinatura na súmula dos jogos. Somente poderiam participar das disputas jogadores que não fossem analfabetos, que 
Artigo | O futebol como um instrumento de inserção étnica no Rio de Janeiro: 1888-1930 (PEREIRA, William E. Nunes; AZEVEDO, Luiz Vinícius de)

soubessem assinar seus nomes na súmula, até por isso era sustentado e defendido pelos grandes clubes a presença de jogadores estudantes, na tentativa de provação de que apenas o estudante poderia jogador futebol. Essa medida dificultou a vida de muitos jogadores de pequenos times, pois muitas vezes "descobria-se um jogador numa pelada, num clube de subúrbio, saber jogar futebol ele sabia, não sabia era ler e escrever" (FILHO. 2010. p.100). Mesmo com pouca capacidade de interferência política direta, os clubes pequenos contrataram professores especificamente para ensinar os jogadores analfabetos a escreverem seus nomes nas súmulas. Além disso, quem possuía emprego considerado subalterno era cortado dos campeonatos, o que fez Manteiga largar o emprego na marinha, para ser contratado pela Casa Leitão, ao se transferir para o América, em 1921, culminando em um dos casos, já citados aqui, de explicitação do racismo da época.

Santos (2010) nos oferece a notícia do Correio da Manhã de 1916, em que explicitava a Lei de Amadorismo que a Liga Metropolitana havia homologado, onde, na prática, era uma caça aos jogadores trabalhadores, iniciando um conflito político, com a discussão chegando até ao Congresso Nacional, em que, basicamente, os prejudicados eram os clubes de subúrbio, como por exemplo, o "Carioca, clube formado por operários da Fábrica de Fiação e Tecelagem Carioca, teve 25 atletas indiciados pela Comissão de Sindicância por não estarem de acordo com as determinações da Lei de Amadorismo da Liga”. (SANTOS, 2010. p.145). Para ilustrar a situação, a carta enviada ao jornal O Imparcial em agosto de 1913, presente em Pereira (1998) já evidenciava a postura segregacionista da Liga:

(...) Para pertencer ao quadro de jogadores da Liga Metropolitana é mister que o proposto não seja cocheiro, carroceiro, cavoqueiro, barbeiro, soldado (praça de pret.), caixeiro de venda, de hotel, de botequim e uma porção de cousas mais, profissões que, no entender dos ilustres homens que inventaram esse regulamento, irão desmoralizar e deslustrar os brios da Liga Metropolitana.

Quer dizer: os clubs só podem registrar estudantes, oficiais das corporações armadas, empregados públicos e... O que mais? Não sei. É crível, sr. Redator, que os vinte clubs da liga possa (sic.) manter cada um dos teams com jogadores que pertençam exclusivamente a essas profissões? (... $)^{17}$

17 “Foot-ball”, O Imparcial, 14 de agosto de 1913. 
Artigo | O futebol como um instrumento de inserção étnica no Rio de Janeiro: 1888-1930 (PEREIRA, William E. Nunes; AZEVEDO, Luiz Vinícius de)

O Vasco da Gama também passou por um incidente de exclusão da liga em que os grandes clubes cariocas estavam. O clube, inclusive, possui, também, papel importante na inserção do negro e das classes mais desprivilegiadas no futebol, dandoas prestígio social, de certa forma. O clube em 1919 possuía a prática, anormal ao seu tempo, de contratações de jogadores negros para o elenco. Se fazendo valer o capital de seus diretores donos de grandes, médias e pequenas casas de comércio, o Vasco contratou 6 jogadores da equipe do Engenho de Dentro, então campeão da Liga Suburbana, entre eles o goleiro negro Nelson Conceição, conhecido como Chauffer (SANTOS, 2010). Com sua subida para primeira divisão do campeonato carioca, ao se sagrar campeão da Série B do campeonato, em 1922, o Vasco trouxe consigo no elenco jogadores negros e pardos, para a disputa do campeonato de 1923, junto aos grandes clubes de composição branca entre os atletas e contrariando todas as expectativas foi campeão do campeonato, perdendo curiosamente apenas para o Flamengo. A despeito, o feito do Vasco, mostrava que a vantagem de ser de alta classe social, estudante, branco, estava desaparecendo no futebol, a pluralidade social se apresentou também como caminho para vitória.

Todavia, a conquista vascaína pôs em xeque a hegemonia elitista do futebol, iniciando um embate entre o amadorismo, defendido pelas vias institucionais, e o profissionalismo, caminho orgânico que o futebol estava tomando em suas relações econômicas. Em 1924, criou-se a Associação Metropolitana de Esportes Athleticos (AMEA), uma liga fundada pelos grandes clubes, culminando na exclusão do Vasco da Gama, alegando que o clube não possuía estádio próprio. Porém, na verdade, o problema era outro, a AMEA, propôs diretamente ao Vasco a exclusão de doze de seus jogadores, por coincidência os negros e os e trabalhadores de fábrica, em troca de sua filiação à instituição. O clube permaneceu na Liga Metropolitana de Desportos Terrestres, que a essa altura já se aceitava, em certa medida, a pluralidade social que o futebol abarcava. A nova associação tinha como propósito a manutenção do amadorismo no futebol carioca, impondo normas e sanções aos clubes, procurando criar um perfil padrão de condições de jogo e atletas. E, com apoio da Confederação Brasileira de Desportos, a participação no campeonato brasileiro de futebol, por parte dos times do Rio, passaria por uma seleção dos clubes participantes da AMEA. Para que 
Artigo | O futebol como um instrumento de inserção étnica no Rio de Janeiro: 1888-1930 (PEREIRA, William E. Nunes; AZEVEDO, Luiz Vinícius de)

as acusações de segregação e racismo fossem relativizadas, o Bangu foi incorporado à liga, a convite do Fluminense, mostrando que negros trabalhadores de fábrica poderiam ser inscritos nos jogos.

Outro clube de composição mais democrática entre os atletas era o São Cristóvão, que por sinal foi o que mais sofreu com as sanções impostas pela associação ${ }^{18}$. Criou-se uma Comissão de Sindicância ${ }^{19}$ para a fiscalização dos clubes, onde era levantado a vida dos atletas para que se soubesse como viviam e se podiam viver com o que ganhavam, dado os gastos que o futebol necessitava.

Se não trabalhassem seriam cortados. Se trabalhassem e ganhassem pouco, uma quantia que não bastasse para a vida que eles levavam, seriam cortados. E se trabalhassem, e se ganhassem bastante, ainda teriam de passar pela prova terrível de bê-á-bá.

Acabara-se o tempo de o jogador só precisar saber assinar o nome na súmula. Se não soubesse escrever e ler corretamente, e na presença de alguém assim como o presidente da Liga, estava cortado.

(...) A papeleta de inscrição tornou-se quase um exame de primeiras letras. Uma porção de perguntas. Nome por extenso, filiação, nacionalidade, naturalidade, dia em que nasceu, onde trabalha, onde estuda, etc., etc. (FILHO. 2010. p.131)

Tal medida pareceu ter seu êxito, os campeonatos cariocas de 1924 e de 1925 foram conquistados pelos clubes exclusivamente de brancos e de elite, Fluminensee Flamengo, respectivamente. E o combinado de jogadores cariocas, compostos por ambos os clubes foram campeões do campeonato brasileiro. A hegemonia foi representada até na seleção brasileira convocada para o sul-americano de 1925, em Buenos Aires, com Friedenreich como único pardo do time ${ }^{20}$. Porém, a campanha do São

\footnotetext{
18 "A Comissão de Sindicância da AMEA foi, apesar de tudo, pra cima do São Cristóvão. Um clube que tinha pretos ficava sob suspeita. O Bangu era um caso à parte." (FILHO, 2010. p. 133).

19 "Um dos fatos marcantes citados por Caldas (1990) que contribuiu para o efetivo atraso ao profissionalismo ocorreu com a AMEA em 1925 ao destituir o pagamento de bichos e estabelecer 16 quesitos para serem aceitos pelos clubes candidatos à filiação. Dentre estes o item de número nove instituía uma Comissão de Sindicância (CS) permanente, cujo objetivo era realizar pesquisas sobre a vida social e profissional dos jogadores" (REIS et al. 2013, p. 294).

${ }^{20} \mathrm{O}$ que não impediu de aparecer ofensas racistas no campeonato. "A multidão invadiu o campo do Barracas aos gritos de 'macaquitos', meteu o pau nos jogadores brasileiros." (FILHO, 2010. p.147) Após confusão envolvendo Friedenreich em uma das partidas contra a Argentina, no sul-americano de 1925.
} 
Artigo | O futebol como um instrumento de inserção étnica no Rio de Janeiro: 1888-1930 (PEREIRA, William E. Nunes; AZEVEDO, Luiz Vinícius de)

Cristóvão, contrariando a proposição da AMEA, foi excelente, sagrou-se campeão do carioca de 1926, com muitos negros e pardos no elenco, ao vencer o Flamengo por 5 a 1, trazendo na vice colocação o Vasco, outro clube de pluralidade, evidenciando que o que se mostrou revolucionário passaria a ser uma tendência, não tinha como se provar e legitimar o racismo imposto pela liga, a vantagem de se misturar etnias se mostrava mais uma vez como determinante do sucesso esportivo. O que fez o América flexibilizar esse fator de composição de elencos, quando o clube deixa de impor barreiras à chegada de jogadores negros, fazendo Mario Filho reorganizar os times da zona sul, de brancos, como o Flamengo, Fluminense, Botafogo, e os times da zona norte, cada vez mais inclusivos, o Vasco, São Cristóvão, Bangu, Andaraí e, agora... o América.

\section{Raça e representatividade}

Na sociedade como um todo a representação de todos os grupos sociais cria sentidos para os indivíduos e consequências subjetivas. No entanto, algumas representações ganham maior visibilidade e passam a ser consideradas, de forma errônea, como expressão da realidade social. Na sociedade brasileira, assim como em outras mundo a fora, as representações que prevalecem com maior visibilidade, institui sentidos de "normalidade" e "anormalidade", estabelecendo como norma padrão o homem branco, assim como vimos aqui, nas exaustivas tentativas de criação de perfil padrão de jogador, branco e estudante no futebol carioca. Tal hegemonia, foi construída mediante a ótica eurocêntrica e, segundo Judith Butler (2000), os indivíduos que não correspondem a esse padrão são vistos como abjetos, e excluídos socialmente.

O abjeto designa aqui precisamente aquelas zonas "inóspitas" e "inabitáveis" da vida social, que são, não obstante, densamente povoadas por aqueles que não gozam do status de sujeito, mas cujo habitar sob o signo do "inabitável" é necessário para que o domínio do sujeito seja circunscrito. (BUTLER, 2000, p. 155)

A abjeção social faz das características corporais e dos fenótipos, elementos através dos quais se pode homogeneizar os sujeitos e naturalizar identidades, generalizando-os. A partir de teorias biológicas errôneas, e produções científicas que 
Artigo | O futebol como um instrumento de inserção étnica no Rio de Janeiro: 1888-1930 (PEREIRA, William E. Nunes; AZEVEDO, Luiz Vinícius de)

naturalizaram a hierarquização racial, o tratamento abjeto do africano escravizado, e seus descendentes, foi transformada em teorias racistas que tiveram por base aquilo que na época era considerado biologia científica.

Embora seja cientificamente inadequada a utilização do termo "raça" para diferenciação de seres humanos, o espectro social do termo teve sua construção histórica aliada à constituição política e econômica da sociedade. Silvio Almeida (2019), em sua obra "Racismo Estrutural" oferece o panorama histórico do conceito de raça, nos levando ao século XVI, sobrepondo à expansão mercantilista a responsabilidade de ter criado a base material para a reflexão sobre "unidade e multiplicidade da existência humana", ou seja, a expansão comercial burguesa e a cultura renascentista criaram as bases para o "imaginário filosófico" em que o europeu representava o "homem universal". Já no século XVIII, com o desenvolvimento das ideias iluministas, o conhecimento se volta para observação do homem (imagem da normalidade expressa) em suas diferentes esferas: biológica, econômica, psicológica e linguística. O que criou as bases intelectuais de comparação - e classificação - de grupos de seres humanos a partir das características físicas e culturais. No século XIX, os ideais positivistas trouxeram a junção entre pensamentos discriminatórios e indagações científicas, dando sequência ao pensamento do século passado, a biologia e física passaram a ser utilizadas para justificar as diversidades étnicas, nascendo a ideia de características biológicas e condições climáticas determinavam características psicológicas e intelectuais.

Immanuel Kant, por exemplo, supõe a ideia de superioridade como "talento" natural, onde a própria natureza desenvolveria humanos com qualidades "superiores" através dos conflitos sociais entre forças antagônicas. Segundo Ricardo Gonçalves (2015), esse pensamento de Kant acaba por justificar o imperialismo europeu, onde a superioridade se daria pelo estado intelectual e tecnológico que estas civilizações alcançaram por seus próprios esforços. Apesar de ser um filósofo alemão notável e relevante, que influenciou significativamente vários campos de estudo no ocidente, dando especial ênfase às suas contribuições sobre os ideais de igualdade e de dignidade da pessoa humana, fortalecendo o entendimento da ideia direitos humanos, assim como os pensadores liberais Hobbes, Locke e Rousseau, no mundo jurídico ocidental, o desenvolvimento dessas teorias de determinismo biológico e geográfico 
Artigo | O futebol como um instrumento de inserção étnica no Rio de Janeiro: 1888-1930 (PEREIRA, William E. Nunes; AZEVEDO, Luiz Vinícius de)

ofereceram respaldo científico para o imaginário racista se manter por tanto tempo de forma entranhada na sociedade, vezes velada, vezes explícita.

Pode encarar-se a história humana no seu conjunto como a execução de um plano oculto da natureza, a fim de levar a cabo uma constituição estatal interiormente perfeita e, com este fim, também perfeita no exterior, como o único estado em que aquela pode desenvolver integralmente todas as suas disposições na humanidade. (KANT. 1990, p.15)

Aliás, o calor úmido é favorecedor do forte crescimento dos animais em geral, e breve, surge o Negro, que está bem adaptado ao seu clima, a saber, é forte, corpulento, ágil; mas, que, ao abrigo do rico suprimento da sua terra natal, [também] é indolente, mole e desocupado. (KANT. 1990, p.21)

Clóvis Moura (1994) segue na linha de raciocínio de Silvio Almeida (2019), ao expor que a abordagem de justificação da dominação europeia viu seu conteúdo ser difundido juntamente com o mercantilismo global e, posteriormente, com o capitalismo, adquirindo uma outra roupagem diversa daquela conhecida nos tempos iniciais coloniais, onde "O racismo é atualmente uma ideologia de dominação do imperialismo em escala planetária e de dominação de classes em cada país particular" (MOURA, 1994, p. 29).

Celso Furtado (2000) ao investigar as raízes do imaginário de progresso, chega a um resultado em que é possível fazer ligações com o raciocínio dos autores anteriores. Furtado evidencia que a junção de três vertentes do século XVIII levou à humanidade a compreensão dos ideais iluministas (centrados na racionalidade), liberais (no acúmulo de riqueza) e eurocêntricos (expansão geográfica europeia) como um processo civilizatório global, fazendo com que a propagação das ideias de que o livre mercado, como instrumento de alcançar a harmonia social, imposto pela sociedade europeia ao mundo, levou a sociedade para o imaginário de "progresso" e, posteriormente, com a sociedade industrial, do progresso tecnológico, tido por muitos, de maneira superficial, como sinônimo de desenvolvimento. $\mathrm{O}$ autor, então, conclui que a sociedade burguesa liberal que se constituiu como hegemônica no ocidente foi uma escolha social - um projeto ideológico-político-econômico - e não uma condição natural do desenvolvimento da sociedade, como Adam Smith (1982) supõe. 
Artigo | O futebol como um instrumento de inserção étnica no Rio de Janeiro: 1888-1930 (PEREIRA, William E. Nunes; AZEVEDO, Luiz Vinícius de)

Dessa forma, podemos concluir que os valores de todas as esferas sociais, que constituíram a maior parte das sociedades ocidentais, influenciadas pelo eurocentrismo, foram hegemonizados através de um processo histórico, político, econômico e ideológico, onde o racismo está presente em todas as esferas sociais e institucionais, apresentando hoje enquanto característica intrínseca e, portanto, estrutural da nossa sociedade. A representatividade se torna uma questão fundamental para a construção de perspectivas de vida, principalmente quando a realidade social tende a invisibilizar sua identidade, pois elas podem gerar consequências psicossociais em que o indivíduo absorve a representação social de si, se distanciando e negando sua identidade cultural e étnica.

\begin{abstract}
A invisibilidade e o recalque dos valores históricos e culturais de um povo, bem como a inferiorização dos seus atributos adscritivos, através de estereótipos, conduz esse povo, na maioria das vezes, a desenvolver comportamentos de auto-rejeição, resultando em rejeição e negação dos seus valores culturais e em preferência pela estética e valores culturais dos grupos sociais valorizados nas representações. (SILVA, 2005, p. 22)
\end{abstract}

Quando voltamos a olhar o futebol brasileiro no período analisado, a representatividade negra ganha força, de maneira intrínseca ao sentimento nacionalista que a sociedade brasileira atribuiu à seleção nacional. A instituição, apesar de apoiar a estrutura racista imposta pelas ligas do período, foi instrumento para valorização de muitos dos nossos craques negros, apoiada nas conquistas e atuações dos mesmos pela camisa da seleção, dado a visibilidade que ganharam.

O início do sentimento de identidade nacional da Federação Brasileira de Sports, nome de fundação, se dá no mesmo ano em que foi criada. Na conquista do título, no dia 27 de setembro de $1914^{21}$, da Copa Roca, na Argentina. Porém, o título mais importante para a consagração popular da seleção brasileira e, também, para o sentimento de representatividade negra, foi em 1919, apenas em 5 anos de fundação. A conquista do Sul-Americano, contra o Uruguai, possui algumas características que fazem dela importante. Segundo Leonardo Pereira (1998), em sua obra "Footballmania: uma história social do futebol no Rio de Janeiro, 1902-1938", mesmo com a falta de

\footnotetext{
${ }^{21}$ Disponivel em: https://www.cbf.com.br/selecao-brasileira/noticias/selecao-masculina/copa-roca-oprimeiro-titulo-da-selecao Acesso em 01 dez. 2018.
} 
Artigo | O futebol como um instrumento de inserção étnica no Rio de Janeiro: 1888-1930 (PEREIRA, William E. Nunes; AZEVEDO, Luiz Vinícius de)

representatividade numérica negra, em relação à quantidade de jogadores negros no elenco brasileiro, os torcedores negros, que, segundo ele, compareciam em massa no campeonato daquele ano, protagonizaram uma cena que mostrava a força de uma identidade, que não batia com os padrões estabelecidos pelas entidades do futebol na época, aquele perfil de jogador intelectual, de "boa família", estudante e branco. O autor evidencia uma coluna do jornal "O Imparcial" de 4 de maio de 1919, quando a seleção uruguaia desembarcou no Rio de Janeiro, onde mostra que os torcedores negros, apesar de torcerem para a seleção brasileira, viam em Isabelino Gradín uma representatividade que ultrapassava as fronteiras nacionais e clamavam para que a igualdade racial fosse posta dentro de campo, fazendo do Gradín um aliado para outras formas de identidade.

"O negro Gradim, o formidável forward uruguaio, quando ontem, guiado amavelmente pelo sportsman N. Bittencourt (...), transpunha o portão do Loyd, foi saudado por três marinheiros nacionais, colegas de cor, que, batendo palmas, exclamaram:

- Aí batuta!... Mostra ao branco que o pé de preto é branco."

Deixando os sportsman que acompanhavam o jogador uruguaio rubros de vergonha, o episódio mostrava que não era tão simples a relação da torcida negra e mestiça com o selecionado nacional. (PEREIRA. 1998, p. 176)

No Sul-Americano de 1919, além do uruguaio Gradín, outra figura já citada teve importante papel de representatividade, porém, adicionada à sua influência no sentimento de identidade nacional relacionado ao futebol e à seleção brasileira: Arthur Friedenreich, o autor do gol da conquista do título. O que fez com que, segundo Mario Filho, cronistas da época discutissem a possibilidade de ter sido criada um 'estilo nacional' de se jogar futebol. O jogador saiu desse campeonato apelidado, pelos próprios uruguaios, de "El Tigre". Hoje é considerado o primeiro grande ídolo do futebol brasileiro, embora em sua contemporaneidade já fosse idolatrado.

O futebol que Arthur mostrou na década de 1910, fez com que a seleção brasileira, apoiadora das instituições racistas, que barravam a presença de negros e pardos nos jogos, se rendesse ao seu talento e o jogador figurava na maior parte das convocações, como o único negro, lido na época como "pardo" ou "mestiço", do time, contrastando com os pressupostos assumidamente racistas inclusive da República Velha, onde o presidente Epitácio Pessoa, em 1921, se posicionou contra a presença de 
Artigo | O futebol como um instrumento de inserção étnica no Rio de Janeiro: 1888-1930 (PEREIRA, William E. Nunes; AZEVEDO, Luiz Vinícius de)

negros na equipe brasileira, que se preparava para o Sul-Americano na Argentina, para evitar "desgastes desnecessários para a imagem brasileira” (FILHO, 2010).

O protagonismo de jogadores negros no futebol é um dos fatores mais influentes para a popularização e crescimento do esporte no Brasil. Mario Filho destaca alguns craques que fizeram do futebol uma arte buscaram sua ascensão econômica através do esporte e construíram um dos primeiros gargalos de formação de identidade e autoestima negra, entre eles há destaque para Arthur Friedenreich (“El Tigre”), Fausto dos Santos (a "Maravilha Negra"), Domingos da Guia (o "Divino Mestre") e Leônidas da Silva (o "Diamante Negro" ou "Homem Borracha”).

\section{Considerações finais}

É muito importante situar as posições ocupadas socialmente das etnias no Brasil. O passado escravocrata, recente em comparação ao período estudado, deixou como legado para a população afrodescendente o descrédito social, tido como um povo inferior e menos capaz que o branco. A discriminação e o preconceito racial, herdados dos séculos de exploração, moldaram novas formas de dominação social dentro da estrutura brasileira pós-abolição, onde a manutenção de benefícios materiais e simbólicos, como o esporte, faziam com que uma elite branca reproduzisse e perpetuasse a desqualificação do negro. E, considerando que a sociedade brasileira pós-escravocrata foi caracterizada pela total ausência de políticas públicas afirmativas, que viabilizasse a sua inserção na sociedade de maneira competitiva, restaram ao negro brasileiro as posições sempre mais baixas na escala estrutural de classes sociais, onde o futebol se apresentou como uma esperança para se alcançar algum prestígio e ascensão social.

Tal perpetuação de dominações sociais é evidenciada, por exemplo, na imposição feita pela Liga Metropolitana ao impedir que "pessoas de cor" participassem do campeonato carioca de 1907, favorecendo o Fluminense, o Botafogo, Internacional e Paissandu, clubes participantes dessa edição. Apesar da resistência, o talento dos negros no futebol e o desenvolvimento de clubes fora da elite, como o Bangu, Vasco, e o Campos A.A., foram abrindo a possibilidade para que os negros encontrassem espaço no esporte que se consolidava como o mais popular do país, ajudando a transformar o futebol em um caminho para realização financeira e em um fator de identidade étnica, 
Artigo | O futebol como um instrumento de inserção étnica no Rio de Janeiro: 1888-1930 (PEREIRA, William E. Nunes; AZEVEDO, Luiz Vinícius de)

onde alguns jogadores, pelo seu talento extraordinário, tiveram papel decisivo nessa integração: Friedenreich, Fausto, Domingos da Guia e Leônidas da Silva.

A competitividade criada em seu desenvolvimento, o montante de dinheiro que se movimentava em seu entorno, o 'bicho' que alguns clubes ofereciam aos seus jogadores após as conquistas e as ofertas de emprego, fizeram com que a prática do futebol fosse atrativa principalmente para as pessoas de baixa renda, ou seja, pelos jogadores que tinham dificuldades financeiras na família. Amor ao clube e lazer no futebol se apresentavam mais frequentemente como motivos para a prática do esporte nas camadas sociais de maior renda e foram usados como argumento para manutenção amadorismo, defendido pelas instituições do futebol. A profissionalização, por sua vez, abria espaço para os jogadores negros de maior talento, permitindo que eles pudessem ter sua carga de trabalho amenizada, dedicando-se mais ao esporte, de tal maneira a desenvolver seu talento e fazendo dele um caminho para representatividade, autoestima e realização financeira.

Hoje, talvez, vivamos um curioso processo em que algumas das conquistas de integração étnica do começo do século passado estejam sendo revertidas. De um lado, com o crescimento da importância das escolinhas e dos empresários, com redução dos campos "de várzea", já não basta o talento nas peladas informais para que um bom jogador consiga se lançar no futebol profissional. Por outro lado, com a transformação dos estádios em arenas e o concomitante aumento geral de preços, os ingressos já não são mais acessíveis a todos os segmentos sociais, postura já utilizada no período analisado, com o surgimento de arquibancadas para sócios. Como consequência, ainda como herança dos séculos de escravidão, os negros são, sistematicamente, afastados dos estádios, dado que maior parte da classe trabalhadora, desprivilegiada economicamente é negra.

Atualmente, a imagem de "normalidade social" continua sendo a do homem branco cis, apesar de avanços nas instituições, e por isso, o futebol feminino ainda sofre em suas condições de financiamento e visibilidade, e, de certa forma, analogamente ao sentimento de invisibilidade que o negros viveram, me parece que a comunidade LGBTQ+ sofre uma pressão para invisibilizar suas orientações sexuais no esporte, o que pode afastar a comunidade do esporte, suscitando estudos futuros. 
Artigo | O futebol como um instrumento de inserção étnica no Rio de Janeiro: 1888-1930 (PEREIRA, William E. Nunes; AZEVEDO, Luiz Vinícius de)

\section{Referências}

Almanaque dos esportes. Futebol: origens brasileiras. Produção: Ancine. [S.I.]: Ancine,

$2014 . \quad$ Disponível em:

https://www.youtube.com/watch?v=4nCTVPBMdjk\&index=12\&list=WL\&t=0s Acesso em: 18 nov. 2018.

BUTLER, Judith. Corpos que pesam: sobre os limites discursivos do "sexo". In: LOURO, Guacira Lopes (org.). O corpo educado. Pedagogias da sexualidade. Belo Horizonte: Autêntica, 2000, p. 155.

CARVALHO, Beth. O velho charme inglês na paisagem de Santos, p. 01. 1982.

Disponível em: http://www.novomilenio.inf.br/santos/h0150g.htm Acessado em 25 de abril de 2020

DOMINGUES, Petrônio José. 0 mito da democracia racial e a mestiçagem em são paulo no pós-abolição (1889-1930). Universidade de São Paulo, São Paulo, 2001.

FERNANDES, Florestan. A integração do negro na sociedade de classes: o legado da raça branca. São Paulo: Editora Globo, 2008.

FILHO, Mario. O negro no futebol brasileiro. Rio de Janeiro: Mauad, 2003. 5 a edição, 2010.

FURTADO, C. Introdução ao desenvolvimento: enfoque-estrutural. Rio de Janeiro: 3 ed., Paz e Terra, 2000.

GONÇALVES, Paulo Cesar. Procuram-se braços para a lavoura: imigrantes e retirantes na economia cafeeira paulista no final do Oitocentos. Revista Brasileira de História. São Paulo, v. 34, no 67, p. 283-308, 2014.

GONÇALVES, Ricardo Juozepavicius. A superioridade racial em Immanuel Kant: as justificações da dominação europeia e suas implicações na América Latina, 2015.

GOTO, Vanessa Strowitzki. A herança histórica do negro brasileiro e o dilema entre políticas públicas redistributivas e de reconhecimento. Anais do V Simpósio Internacional Lutas Sociais na América Latina, 2013.

HAHN, Alexandre. "Das diferentes raças humanas", de Immanuel Kant. Kant e-Prints:

Série 2, v. 5, n. 5, número especial, jul-dez., 2010.

KANT, Immanuel. Ideia de uma História Universal com um Propósito Cosmopolita.

Lisboa: Edições 70, Trad. Artur Morão, 1990. Oitava proposição, p. 15.

MACHADO, Wesley. Saudosas Pelejas: A história centenária do Campos Athletic

Association. Campos dos Goytacazes, RJ, 2012.

MOLINARI, Carlos. Nós é que somos banguenses, 2004. Disponível em: http://www.bangu.net/informacao/livros/nosequesomosbanguenses/apresentacao.ph p p Acesso em 30 nov. 2018.

MORAES, Hugo Silva. Tempos de crise: a liga metropolitana de desportes terrestres e a cisão do futebol carioca (1917 - 1923). Anais do XXVI Simpósio Nacional de História ANPUH. São Paulo, julho 2011. MÓSCA, Hugo Motta Bacêllo. Fatores Institucionais e Organizacionais que Afetam a Profissionalização da Gestão do Departamento de Futebol dos Clubes, Rio de Janeiro: PUC, Departamento de Administração, 2006.

MOURA, C. O racismo como arma ideológica de dominação. In: Revista Princípios, São Paulo, n. 34, agosto a outubro de 1994, p. 28-38. 
PEREIRA, Leonardo Affonso de Miranda. Footballmania: uma história social do Futebol no Rio de Janeiro (1902-1938). Universidade Estadual de Campinas, Campinas, 1998.

REIS, Rômulo. TELLES, Silvio. MOREIRA, Jorge. PEREIRA, Lamartine. Primeiros passos organizacionais no futebol brasileiro (1894-1933): uma análise no campo da gestão esportiva. Revista Brasileira de História \& Ciências Sociais Vol. 5 № 9, Julho de 2013.

SANTOS, João Manuel Casquinha Malaia. Revolução Vascaína: a profissionalização do futebol e a inserção sócio-econômica de negros e portugueses na cidade do Rio de Janeiro (1915-1934). Universidade de São Paulo, São Paulo, 2010.

SANTOS, Marco Aurélio. Lutas políticas, abolicionismo e a desagregação da ordem escravista: Bananal, 1878-1888. Almanack. Guarulhos, n.11, p.749-773, dezembro de 2015.

SEVCENKO, Nicolau. A Capital Irradiante: técnicas ritos e ritmos do Rio. In: SEVCENKO, Nicolau (org). História da vida privada no Brasil, vol. 4. São Paulo: Companhia das Letras, 1998. p.571.

SILVA, Ana Célia da. A desconstrução da discriminação no livro didático. In: MUNANGA, Kabengele. (org.) Superando o Racismo na Escola. 2a edição revisada [Brasília]: Ministério da Educação, Secretaria de Educação Continuada, Alfabetização e Diversidade, 2005.

SMITH, A. A Riqueza das Nações: Investigação Sobre sua Natureza e suas Causas. São Paulo: Abril Cultural, 1982

SOARES, Antônio Jorge. História e Invenção de Tradições no Campo do Futebol. Estudos Históricos, no 23. 1999.

STEPAN, Nancy Leys. Eugenia no Brasil, 1917-1940. In: HOCHMAN, G., and ARMUS, D., orgs. Cuidar, controlar, curar: ensaios históricos sobre saúde e doença na América Latina e Caribe. Rio de Janeiro: Editora FIOCRUZ, 2004. 